\title{
REGRESSION MODELS FOR SAFFRON YIELDS IN IRAN
}

\author{
Sanaeinejad, S.H., Hosseini, S.N \\ Faculty of Agriculture, Ferdowsi University of Mashhad, Iran sanaei_h@yahoo.co.uk, \\ nasir_nbm@yahoo.com,
}

Abstract: $\quad$ Saffron is an important crop in social and economical aspects in Khorassan Province (Northeast of Iran). In this research we tried to evaluate trends of saffron yield in recent years and to study the relationship between saffron yield and the climate change. A regression analysis was used to predict saffron yield based on 20 years of yield data in Birjand, Ghaen and Ferdows cities. Climatologically data for the same periods was provided by database of Khorassan Climatology Center. Climatologically data included temperature, rainfall, relative humidity and sunshine hours for Model I, and temperature and rainfall for Model II . The results showed the coefficients of determination for Birjand, Ferdows and Ghaen for Model I were 0.69, 0.50 and 0.81 respectively. Also coefficients of determination for the same cities for model II were $0.53,0.50$ and 0.72 respectively. Multiple regression analysis indicated that among weather variables, temperature was the key parameter for variation of saffron yield. It was concluded that increasing temperature at spring was the main cause of declined saffron yield during recent years across the province. Finally, yield trend was predicted for the last 5 years using time series analysis.

Keywords: $\quad$ saffron, crop weather model, yield

\section{INTRODUCTION}

Saffron is a plant with a wide ecological, physiological and phonological characterizes. As a result, there is a great deal of controversy related to ecological, phonological and standard type of climate suitable for this plant. In Iran saffron grows well under temperate and dry climates, its vegetative

Please use the following format when citing this chapter:

Sanaeinejad, S.H. and Hosseini, S.N., 2009, in IFIP International Federation for Information Processing, Volume 293, Computer and Computing Technologies in Agriculture II, Volume 1, eds. D. Li, Z. Chunjiang, (Boston: Springer), pp. 509-518. 
growth coincides with cold weather and freezing conditions. Usually the maximum temperature for October, November and December in the southern parts of Khorassan-the main saffron growing area of the Iran-does not exceed $20^{\circ} \mathrm{C}$, while the minimum temperature reaches $0^{\circ} \mathrm{C}$. The influence of weather variation has been determined for different crops in many parts of the world. Mashayekhi et al. (2006) assessed the effect of environmental temperature on flowering behavior of saffron. The results showed that mean and minimum temperature were the most important driving force to determine flower emergence and flower initiation in saffron, respectively. Behdani et al (2003) developed a model for saffron flowering time. Their aim was to develop a thermal model that can be used for prediction of saffron flowering time. They concluded that developing rate (DR) of saffron has a unique response to mean September temperature. Sanaeinejad et al (2007) studied the effect of meteorological factors on phonological stage of wheat in Iran. Results showed that, the most sensitive stages of wheat growth are an thesis, milky and waxy stages. Most researches considered the impact of weather on crop, but study of long-term trend for saffron yield using crop weather model is lacking in Iran. In this paper, we tried to evaluate the trends of saffron yield in recent years and study of relationship between saffron yield and climate variation for the main areas of Saffron cultivation in South Khorassan Province of Iran.

\section{MATERIAL AND METHODS}

\subsection{Trend of saffron yield}

In this study Data of Saffron yield in three main areas of cultivation in South Khorassan (Birjand, Ferdows and Ghaen) were collected. The data from 1983 to 2005 were provided by Khorassan Jahade-Agriculture Organization. Table 1 shows the average of long-term saffron yield in this period.

Table1. Average of saffron yield in area under study

\begin{tabular}{cccc}
\hline City & $\begin{array}{c}\text { Average of saffron yield } \\
(\mathrm{kg} / \mathrm{ha})\end{array}$ & Period & year \\
\hline Birjand & 5.66 & 21 & $1983-84,2003,04$ \\
Ferdows & 5.16 & 22 & $1983-84,2004-05$ \\
Ghaen & 5.61 & 17 & $1987-88,2003-04$ \\
\hline
\end{tabular}


Study of yield change trend was conducted on the basis of time series analysis. A time series is a sequence of observations which are ordered in time. If observations are made on some phenomenon throughout time, it is most sensible to display the data in the order in which they arose, particularly since successive observations will probably be dependent. Time series are best displayed in a scatter plot. The series value $\mathrm{Y}$ is plotted on the vertical axis and time $t$ on the horizontal axis.

In time series the equations are showed in the linear and curvilinear forms (equations 1,2 and 3 ).

$$
\begin{aligned}
& Y_{t}=b_{1}+e_{t}(1) \\
& Y_{t}=b_{1}+b_{2} t++e_{t} \\
& Y_{t}=b_{1}+b_{2} t+b_{3} t^{2}+e_{t}
\end{aligned}
$$

In which:

$Y_{t}$ : Variable value in each time $\mathrm{t}$ (here is, saffron yield per year)

$b:$ Coefficients of model

$e_{t}$ : Error of Y estimates in each year.

In this study, both linear and nonlinear (degree 2) function were properly fitted to yield data. Yield trend in time series, was predicted for 5 years after the last datum. In this study, for predicting trend of saffron yield exponential smoothing was used.

\subsection{Evaluation of correlation between yield and weather indices}

In order to determine relationship of saffron yield in areas under study, weather indices of about 20 years data including monthly rainfall, monthly average minimum temperature and average maximum temperature and average temperature, monthly average minimum and maximum relative humidity and monthly total of sunshine hour's were collected from database of Khorassan Climatology Center. In this research two models were used. For model I all of the top parameters and for model II temperature and rainfall were used. Relationship of yield to weather factors was determined by simple and multiple regressions. For this reason, at first, saffron yield (Y) was analyzed with monthly weather factor for all areas under study separately by regression in order to determine climatic indicator for each area and also to determine the most important month affecting saffron yield. Then, by multiple regressions, relation of saffron yield (Y) to climatic variable was determined for each area. The method used was Backward Stepwise Regression. Thus, the final model describing yield was calculated 
by the most important climatic variables. For analysis time series the software Minitab, ver. 13.1 and for regression analysis JMP ver 4 were used.

\section{RESULT AND DISCUSION}

\subsection{Trend of saffron yield}

Trend of saffron yield for all areas under study were similar. So, trend of saffron yield followed second degree model. The equation of trend of saffron yield in Birjand, Ferdows and Ghaen are defined by equation 4, 5 and 6 , respectively. Figure 1, 2 and 3 show trend of saffron yield for area under study.

Birjand:

$$
Y=5.56+0.23(t)-0.016\left(t^{2}\right)
$$

Ferdows:

$$
Y=5.81+0.12(t)-0.012\left(t^{2}\right)
$$

Ghaen:

$$
Y=4.57+0.51(t)-0.034\left(t^{2}\right)
$$

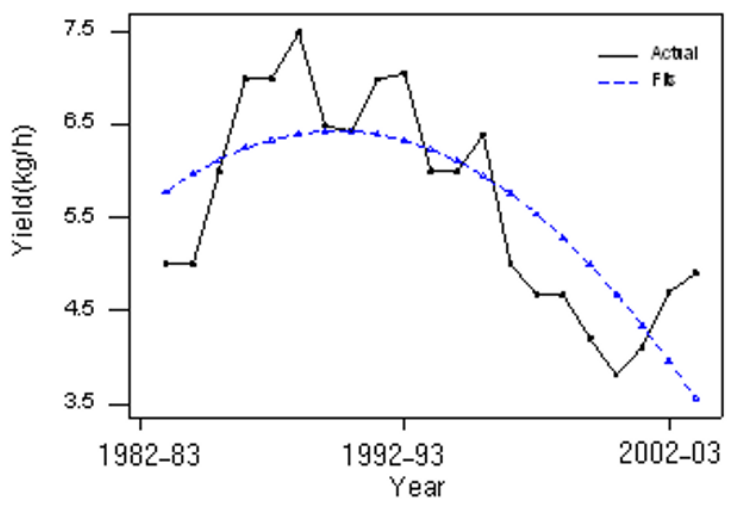

Figure 1. Trend analysis of saffron yield in Birjand. 


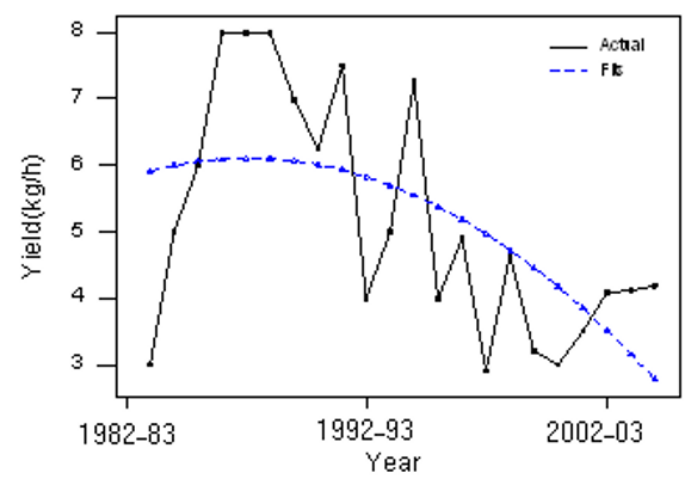

Figure 2. Trend analysis of saffron yield in Ferdows

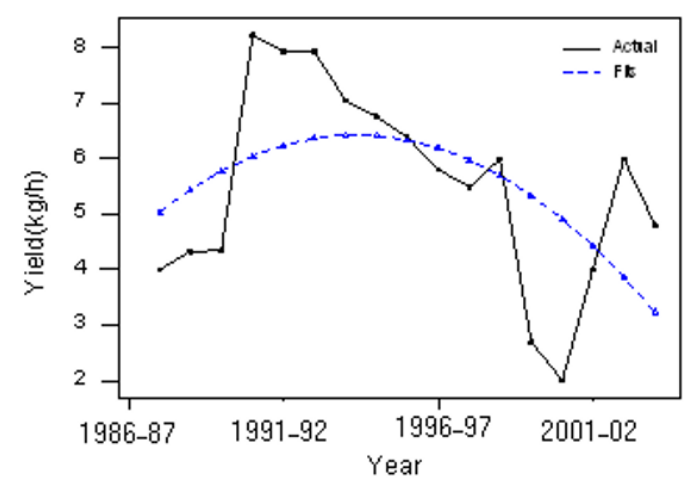

Figure 3. Trend analysis of saffron yield in Ghaen

Results show that there are two characteristic parts for this 20 years period. For the first 10 years we observed yield increase and at the second 10 years we observed yield reduction. Thus, the aim was to relate yield reduction to change of climatic indicators, to determine contribution of these factors affecting yield changes.

\subsection{Relation of weather variability to saffron yield}

\subsubsection{Birjand}

The Results of regression analysis among the yield at 21 years of Birjand and weather variability after omitting variables by stepwise technique showed that minimum and maximum temperature of April and sunshine hour's of Feb have significant effects on saffron yield variation for Birjand. Regression equations for two models are as follows: 


$$
\begin{aligned}
& Y=15.27-0.02 \times\left(T_{\text {avg-Apr }}\right)-0.53 \times\left(T_{\min -A p r}\right)-0.02 \times\left(\operatorname{Sun}_{-F e b}\right) \quad \text { Model } \\
& Y=14.86-0.38 \times\left(T_{\min }-A p r\right)-0.22 \times\left(T_{\max }-A p r\right) \quad \text { ModelII }
\end{aligned}
$$

Diagram of two variable regressions in model II is shown in figure 4 . The observed and predicted model yields are shown in figure 5 .

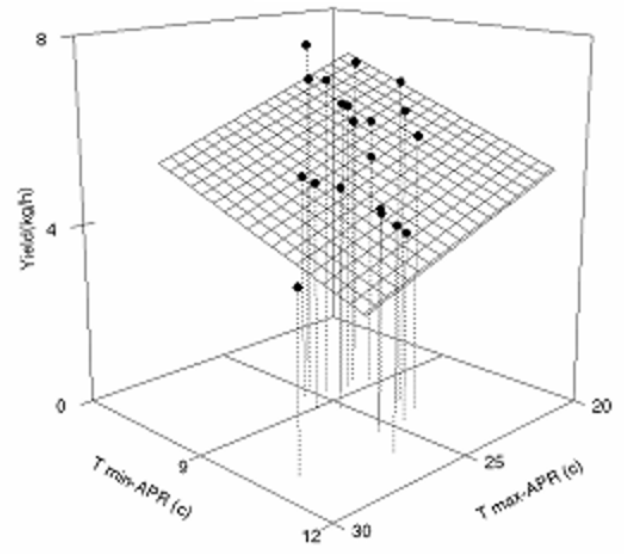

Figure 4. Effect of weather factors on saffron yield in Birjand

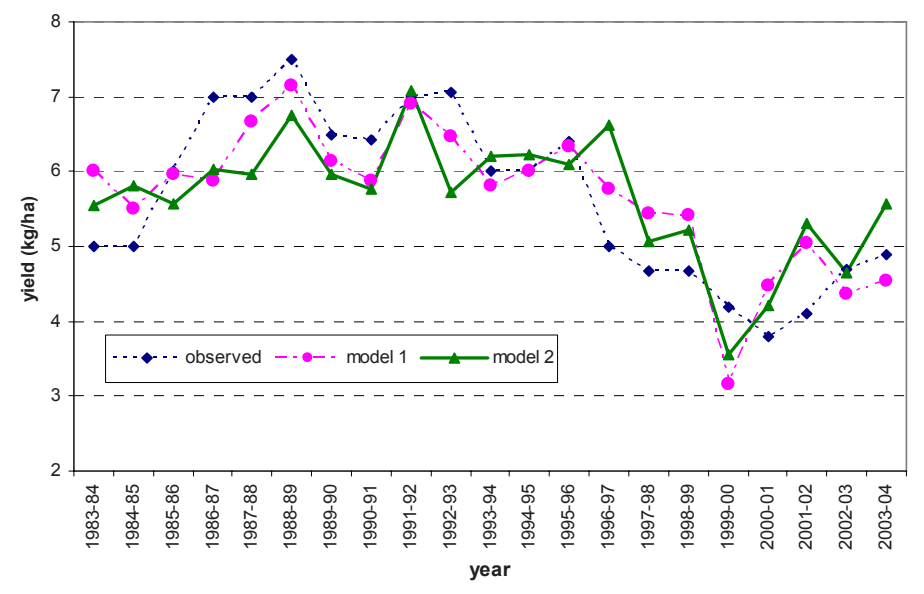

Figure 5. Observed and predicted saffron yield in Birjand.

\subsubsection{Ferdows}

Results for two models are similar for Ferdows. In Ferdows the most important factor was minimum temperature of April. The regression equation for yield and minimum temperature of April was as figure 6. Figure 7 shows the actual and predicted yield model in Ferdows. 


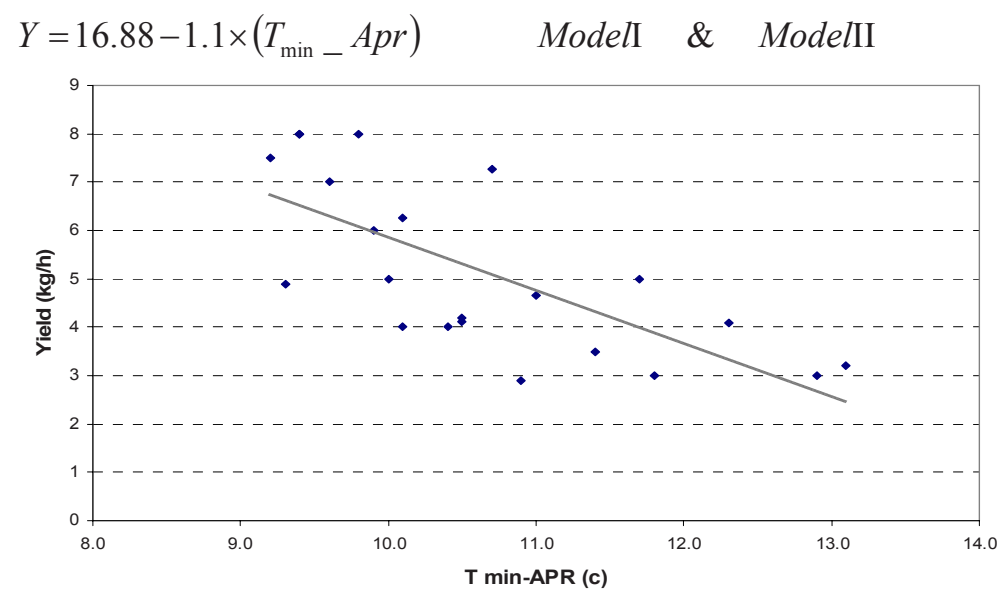

Figure 6. Effect of weather factor on saffron yield in Ferdows.

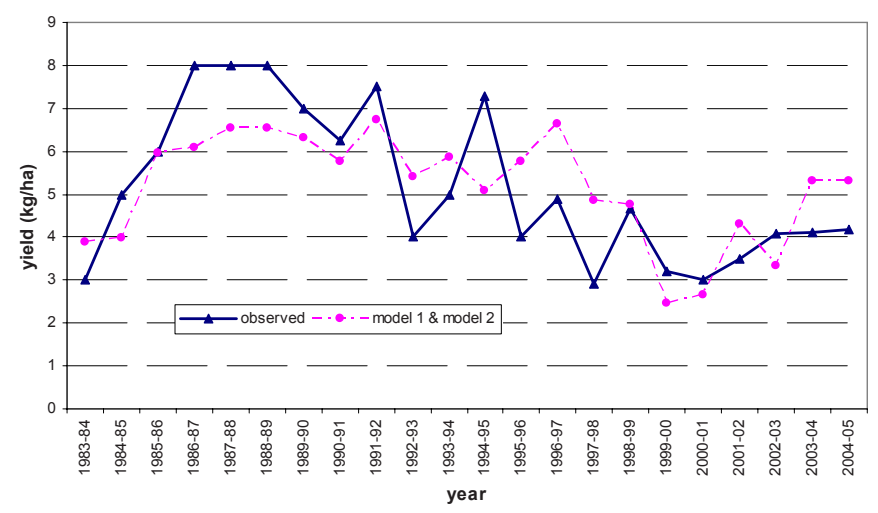

Figure 7. Observed and predicted saffron yield in Ferdows.

\subsubsection{Ghaen}

The results of two models For Ghaen were different. In model I maximum relative humidity of April and monthly total of sunshine hours of April and Mars and for model II maximum temperature of April and maximum and average temperature of March were important (equations 10 and 11). Also figure 8 shows the actual and predicted model yields in Ghaen. The predicted values did not differ much from those observed value.

$$
\begin{array}{ll}
Y=13.87+0 / 07\left(R_{\max -A p r}\right)-0.02\left(\text { Sun }_{- \text {Mar }}\right)-0.03\left(\text { Sun }_{- \text {May }}\right) & \text { Model I } \\
Y=21.76+1.14\left(T_{\text {avg }}-\text { Mar }\right)-1.17\left(T_{\max }-\text { Mar }\right)-0.42\left(T_{\max }-\text { Apr }\right) & \text { ModelII }
\end{array}
$$




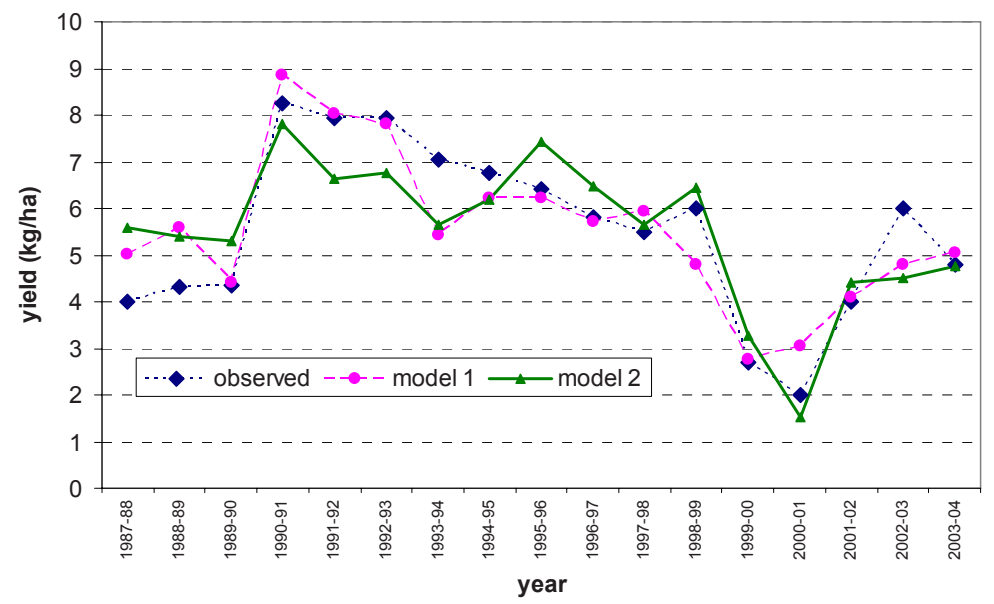

Figure 8. Observed and predicted saffron yield in Ghaen.

Table 2. The Equation and coefficients of determination for model $\mathrm{I}$

\begin{tabular}{llc}
\hline CITY & EQUATION & $R^{2}$ \\
\hline Birjand & $Y=15.27-0.02 \times\left(T_{\text {avg-Apr }}\right)-0.53 \times\left(T_{\min -A p r}\right)-0.02 \times\left(\right.$ Sun $\left._{-F e b}\right)$ & 0.69 \\
Ferdows & $Y=16.88-1.1 \times\left(T_{\min -A p r}\right)$ & 0.50 \\
Ghaen & $Y=13.87+0 / 07\left(R_{\max -A p r}\right)-0.02\left(\right.$ Sun $\left._{- \text {Mar }}\right)-0.03\left(\right.$ Sun $\left._{-M a y}\right)$ & 0.81 \\
\hline
\end{tabular}

Table 3. The Equation and coefficients of determination for model II

\begin{tabular}{llc}
\hline CITY & EQUATION & $R^{2}$ \\
\hline Birjand & $Y=14.86-0.38 \times\left(T_{\min -A p r}\right)-0.22 \times\left(T_{\max -A p r}\right)$ & 0.53 \\
Ferdows & $Y=16.88-1.1 \times\left(T_{\min -A p r}\right)$ & 0.50 \\
Ghaen & $Y=21.76+1.14\left(T_{\text {avg-Mar }}\right)-1.17\left(T_{\max -\text { Mar }}\right)-0.42\left(T_{\max -A p r}\right)$ & 0.72 \\
\hline
\end{tabular}

Maximum coefficients of determination $\left(R^{2}\right)$ were 0.81 and 0.72 for Ghaen in model I and model II respectively. Minimum coefficient of determination ( $R^{2}$ ) were 0.50 for Ferdows. It means $50 \%$ of yield variation is described by weather factors. Finally, yield trend was predicted for the last 5 years after the last datum using time series analysis. These results showed in figures 9,10 , and 11 . The trends of yield for the last 5 years for 3 cities are descending (redlines in figures). 


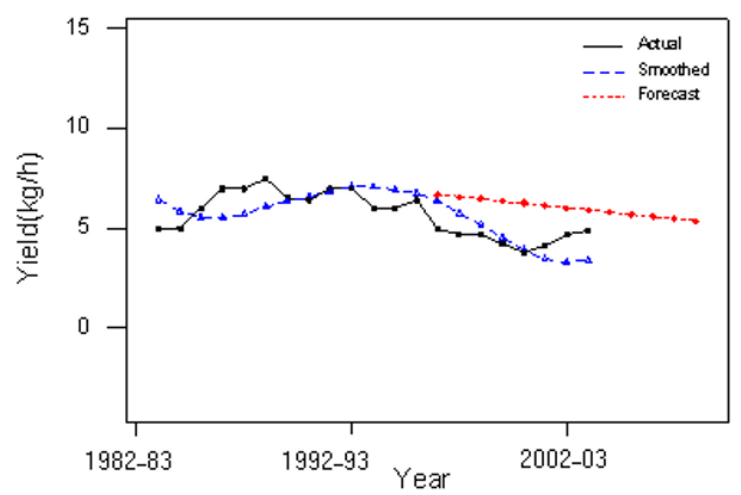

Figure 9. Trend of prediction of saffron yield in Birjand.

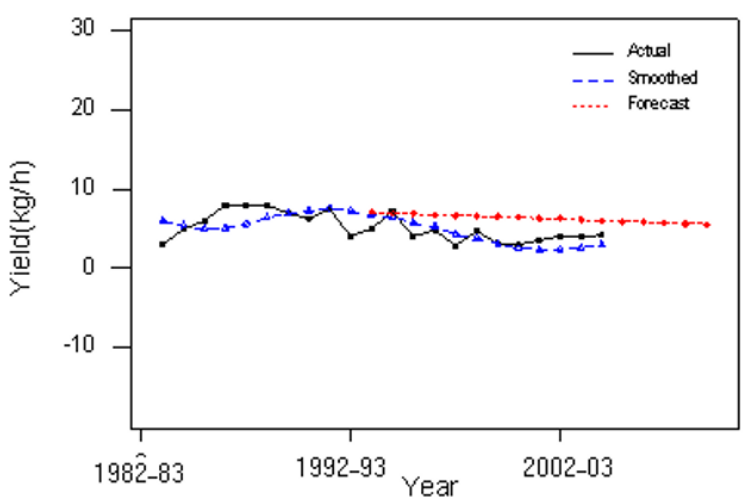

Figure 10. Trend of prediction of saffron yield in Ferdows.

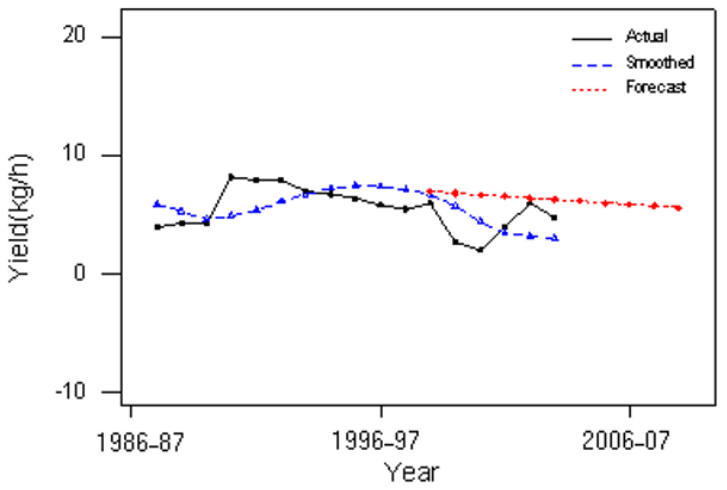

Figure 11. Trend of prediction of saffron yield in Ghaen. 


\section{CONCLUSION}

The results showed that the models can predict saffron yield satisfactory and difference between actual and predicted yields were not considerable, especially in Ghaen and Birjand (figure 9, 10 and 11). The results of coefficients of determination showed that $\left(R^{2}\right)$ for model I is higher than model II . Also findings showed that reduction of saffron yield in South khorasan Province during 10 years has been caused significantly by weather factors in spring month particularly temperature. It is concluded that temperature (maximum, minimum and average) of spring month (March and April) is very important and increasing trend in spring temperature was the main cause of declined saffron yield during recent years across the province. Rainfall, relative humidity and monthly total of sunshine hour's factors hold a less importance in yield saffron in regression analysis.

\section{REFERENCES}

Behdani, M., A. M. Nassiri, and A. A. Koocheki. 2003. Modeling Saffron Flowering Time Across a Temperature Gradient. In proceedings of 2nd International Symposium on Saffron Biology and Technology. 22-25 October. Albacete, Spain.

Črepinšek, Z., L. Kajfež-Bogataj, and K. Bergant. 2006. Modeling of weather variability effect on fitophenology. Ecological Modeling, 194 (1-3): 256-265

Hosseini, M., and A. Mollafilabi, 2006. Spatial and temporal patterns of saffron (Crocus sativus) yield in Khorasan Province and their relationship with long-term weather variation. In proceedings of 2nd International Symposium on Saffron Biology and Technology. 28-30 October, Mashhad, Iran.

Mashayekhi, K., B. Kamkar, and A. Soltani, 2006. The Effect of Corm Weight and Environmental Temperature on Flowering Behavior of Saffron (Crocus Sativus). In proceedings of 2nd International Symposium on Saffron Biology and Technology. 28-30 October, Mashhad, Iran. 